\title{
Kültürü çevirmek: Kültür aktarımı kapsamında çeviri
}

\section{Gökmen GEZER'}

\section{Muhammed Zahit CAN²}

\begin{abstract}
APA: Gezer, G.; Can, M. Z. (2019). Kültürü çevirmek: Kültür aktarımı kapsamında çeviri. RumeliDE
\end{abstract} Dil ve Edebiyat Araştırmaları Dergisi, (17), 355-370. DOI: 10.2900o/rumelide.656917

\section{$\ddot{O} \mathbf{z}$}

Çeviri insanoğlunun başka bir kültürle temasa geçmeye başladığı andan itibaren, iletişim ihtiyacını görmeye yarayan bir araçtır. Ancak çeviri bir dilden başka bir dile yalnızca dilsel kodlarının aktarımı değil; bilakis kodların, belirli bir zaman, mekan, aktör ve konu gibi -en geniş manada bağlam kavramıla açıklanabilecek- olguların birlikte teşekkül ettirdikleri anlamın yine çevirmen adı verilen bir başka aktör tarafından pragmatik bir biçimde algılanarak aktarılması hadisesidir. Tüm bu öğelerin bir araya gelmesi, buluşması, birlikte bir bütün oluşturması ve anlamlı bir icraatın ortaya çıması kültürün düzenleyici gücüyle mümkündür. Kültür, çeviriyi düzenleyici bir nosyon olmakla beraber çeviri tarafından düzenlenen bir olgudur da. Tüm bu tartışma bağlamında mevcut araştırma konu hakkındaki temel çeviribilimsel yaklaşımları incelemiş, geniş bir kaynak taraması (yöntemiyle) ve aktarımıyla bütüncül bir çerçeve çizmeye çalışılmıştır. Öyle görülüyor ki çeviri iki dil arasındaki bir aktarımdan çok iki dil arasında kültürel varlıkların, yine kültürün çizmiş olduğu bir çerçeve kapsamında aktarımı hadisesidir.

Anahtar kelimeler: Kültürel çeviri, çeviri ve kültür, kültür aktarımı, çeviri kültürü.

\section{Translating culture: Translation within the context of culture transfer}

\begin{abstract}
Translation is a tool to meet the need for communication from the moment human beings come into contact with another culture. It is not only the transfer of linguistic codes from one language to another. On the contrary, it is a phenomenon that pragmatic perceptions are conveyed by another actor called translator. It is possible with the regulatory power of culture that elements such as code, time, place, actor and subject come together and form a whole together which leads to a meaningful action. Culture is a notion regulating translation, but it is also regulated by translation. In the context of all this discussion, the present research has examined the main translation-oriented approaches on the subject and tried to draw a holistic framework with a wide search and transfer of resources. It seems that translation is not a transference between two languages but rather a transference of cultural assets between two languages within the framework of culture.
\end{abstract}

Keywords: Cultural translation, translation and culture, cultural transfer, translation culture.

\footnotetext{
1 Dr. Öğrencisi, Sakarya Üniversitesi, Sosyalbilimler Enstitüsü, Çeviribilim ABD (Sakarya, Türkiye), ggezer@gsu.edu.tr, ORCID ID: 0000-0003-2224-8034.

2 Dr. Öğr. Üyesi, Sakarya Üniversitesi, Fen Edebiyat Fakültesi, Ceviribilim Bölümü (Sakarya, Türkiye), zcan@sakarya.edu.tr, ORCID ID: oooo-0003-4765-3693 [Makale kayıt tarihi: 26.09.2019-kabul tarihi: 20.12.2019; DOI: $10.29000 /$ rumelide.656917]
} 
Kültürel gerçeklik bir kurgu niteliği taşıdığından, daima önceden çevrilmiştir. (Niranjana, 1992:172)

\section{Giriş}

Çeviri, diller ve kültürler arası iletişim ve etkileşim sürecinin en önemli (f)aktörü ve her aşamasıyla insan merkezli bir etkinliktir. İnsan deneyiminin ortaya koyduğu birikimin temsilcisi kültür ile adı bir arada sıklıkla kullanılmakta ve bu iki olgunun ayrı ayrı ve/veya beraber kapladıkları alan çeviribilimin yoğun araştırma sahalarından biri olma özelliğini korumaktadır. Kültürün hibrid doğası ve çevirinin dönüşümcü/dönüştürücü gücü buna fazlasıyla imkan vermektedir (Gentzler, 2017:xii). Ayrıca, çeviri eylemi sonucunda ortaya konan performans sadece dilsel ve edimsel bir uygulamayı değil, tarih, kültür, ekonomi, filoloji, antropoloji, coğrafya, politika, psikoloji ve bilişim gibi pek çok semantik ve sosyal eksende farklı araştırma alanlarını da sürece dahil edebilmektedir (Chesterman,2012:6-27). Bu değerlendirme, iletişim ve bilgi aktarım aracı gibi sosyal bir işlevi olan çevirinin (Vardar, 1982:18), tarihsel ve kültürel etmenler üzerinde nasıl etkin bir rol oynadığını hatırla(t)mak için gerekli bir tespittir. Üstelik, kültür-dil bağlamı penceresinden, çevirinin, günümüzde, sadece belli disiplinler içinde ve belli kavramlarla anılmamakta, aksine, adım adım, bilim yapılan her sahada ve her sahaya uygulanabilir bir enstrümana ve bir prensibe dönüşmekte olduğu ifade edilmektedir (Nergaard ve Arduini, 2011:14).

Kültür söz konusu olduğunda, metin geleneğinden inanca, dünya algısından düşüncenin ifade ediliş biçimine kadar her türlü kültürel öğe ve değere dayalı bir farkındalık algılanmaktadır (Malinowiski, 1962:169). Bu farkındalıkla birlikte oluşan hassasiyet, her türlü iletişim mecrasında, başka kültüre ait davranış ve kavramların farklı yönleri ve boyutlarıyla yorumlanmasını, bu gözle değerlendirilmesini ve kültürel anlam katmanlarının ayırt edilmesini öncelikli bir unsur kılmaktadır (Davis, 1977: 21- 57). Bu öncelikli unsur, üstelik pedagojik yaklaşımlarla ifade ediliyorsa, çevirinin dönüşümcü ve/veya dönüştürücü gücünü anlaşılır kılmak adına ziyadesiyle yeterlidir.

Wittgenstein, diğer pek çok eserinde değindiği gibi, Philosophical Investigations / Felsefi Soruşturmalar adlı kitabında da, dilin başlı başına bir hayat biçimi olduğunu ve toplumsal etkileşimi dilin sağladığını savunmaktadır (1958). Wittgenstein'nin bu yargısı kültürün oluşumunda dilin var olduğu ön şartını temellendirir niteliktedir. Benzer şekilde Sapir, her kültürel örüntünün ve sosyal davranışın doğrudan veya dolayl bir iletişim biçimini içermekte olduğunda ısrarcıdır (1956:104). Bu iletişimi sağlayacak olan enstrüman dil ise, kültüre gömülü dili görünür kılacak gerekli aracın çeviri olduğu aşikardır. Çeviri ayrıca, kültürler arası köprüleri kurma ve diğer olan ile aradaki farklılıklara açıklık getirme görevlerini üstlenmektedir. Çevirmenlere gelince, onlar faaliyetlerini, André Lefevere’in dediği gibi, belli bir zaman dilimi içinde belli bir kültürel yaşamın parçalar olarak gerçekleştirmektedirler (1992: 14). Bu değerlendirme, çeviriyi dilsel bir aktarım olmanın ötesine geçiren ve çeviriye kültürler arası bir kimlik kazandıran önemli bir farkındalıktır. Buna ek olarak, Maria Tymoczko, kültürü, insanlar arası farklhlkların kendini en çok gösterdiği mecra olarak resmederek etik, ideolojik ve zaman zaman politik çeviri kararlarının alınacağı ortamların varlığına dair işaretler sunmaktadır (2010:221).

Kültürün bünyesinde barındırdığı din, ekonomi, hukuk, politika, dil ve edebiyat temelli bir takım kural ve norm tümelleri bir kültürün öğelerini oluşturmakta ve tüm bunları paylaşan insanlar aynı kültürden kabul edilmektedirler (Davis, 1977: 21- 57). İki ayrı kültüre ait teamüllerin ve esasların yorumlanması ve anlaşılması, Guy Cook’a göre, söz konusu kural ve davranış örüntülerinin, sözlü-sözsüz iletişim ortamlarında, nasıl ve ne derece paylaşıldığıyla yakından iniltilidir (2003:52). Özetle, Cook'a göre, dil- 
kültür organik ortaklığında biçimlendirilen kültürel yönelimler, çeşitli katmanlarda, dilsel ve kültürel değişkenlere bağlı kalarak, ayrı dil gruplarında bir takım farklılıklar arz edebilmektedir (a.e:53). Bu gerçeklik bir yandan çeviriye olan ihtiyacı yansıtmakta ve aynı paralelde iletişimsel, dilsel ve kültürel edinçlerin gelişiminde rol oynayan çeviri etkinliği üzerine yeni akademik tartışmalar açmaktadır.

Kökünü ve şeklini dilden almasına rağmen, kültür, George Steiner’in After Babel eserinde dediği gibi (1975), başlıbaşına bir anlam transferidir, ve bir metin olarak okunması gerekmektedir. Dolayısıyla, kültürün çevirisi, kültürü meydana getiren her kültürel unsur için ve o unsurla birlikte karmaşık bağlantı noktaları içermektedir. Her biri ayrı kulvarlara ait olsalar da, sosyal etkileşimin ve iletişimin tezahürü olarak, söz konusu bağlantı noktalarında, biribiriyle örtüşen çeviri ürünleri sunulmaktadır. Bu nedenle, çalışmanın amacı, kültür çevirisinde kesişme ve temas alanlarının neler olabileceğine dair bilgi sunmak olarak belirlenmiştir. Birinci bölümde kültür kavramı çeviriyle ilişkilendirilerek izah edilmiştir. İkinci bölüm, kültür - çeviri ilişkisine genel bir bakış sunmaya ayrılmıştır. Üçüncü bölümde, kültür çevirisinin yansıtıldığı kültürel yaşama ait arayüzler, temas alanları şeklinde özetlenmiş, sunabilecekleri olası çeviri zorluklarına değinilmiş ve bunlara uygun çeviri yaklaşımlarına kısaca değinilmiştir. Bu amaçla, pedagoji, iletişim, yazın edebiyatı, siyaset gibi sosyo-kültürel kavram ve alanlardan faydalanılımıştır.

\section{Kültür ve çeviri}

Kültür çeviri ilişkisine bakıldığında, bu iki kavramın birbirini etkilediğinden bahsedilebilir. Kültürün çeviriyi etkileme biçimine öncelikle yer verilecek olunursa, kültürün baştan tanımlanması icap edecektir. Kültür en genel manada insanoğlunun kendisinin yarattığı, biçim verdiği ve sonradan biçim verilmemiş, dönüştürülmemiş doğanın dışında kalan her şeydir. Buradan hareketle çeviri insanoğlunun doğal iletişim gereksinimine bir biçim vererek gerçekleştirmiş olduğu eylemdir tanımlaması yapılırsa, çevirinin de bir kültür ürünü olduğu sonucuna varılması gerekir. Diğer bir kültür tanımlamasına göre de çeviri geçmişten kalan mirası geleceğe taşıması bakımından kültürle organik bir bağ kurmaktadır. Yani kültür tarihsel süreçte sosyal etkileşim sonucunda biçimlenir, bir iletişim formu olan çeviri yoluyla aktarılır ve paylaşılır; böylelikle çevirinin iletişim biçimi cereyan eder. Bu yönüyle de çeviri kültür kavramının nüfuz ettiği bir olgu olarak ele alınma durumundadır.

Konuya çeviri penceresinden bakıldığında ise, çeviri bizzat kültürü başka bir dil-kültür havzasına taşıyıcı rol üstlenmektedir. Kültürel varlıklar dil aracılı̆̆ıyla ve diller arası aktarım aracı olan çeviriyle taşınmaktadır. Bu rolü üstlenirken de kültürün ona biçtiği rolü oynarak bunu gerçekleştirmektedir.

Çeviri aynı zamanda kültür muhafaza edici bir pozisyona sahiptir. Belirli bir kültür havzasındaki kültürel varlığın başka bir kültür havzasına taşınmasında ve bu sayede her iki farklı havzalarda o kültürün var olması, barınması ve bu bakımdan kaybolma riskinin azalması söz konusudur. Diğer yandan mevcut bir kültürel varlığın başka bir kültür havzasında başkalaşması da söz konusu olabilmekte; hatta doğal bir sonuç olarak görülebilmektedir.

Tam tersi bir etkinin ise olasılı̆̆ı daha zayıf görülebilir. Şerif Mardin’in (2011:54) kültür yapılarının bir dereceye kadar özerk yapılar olduğunu söylemesi, onların kolay kolay dönüşemeyeceğini söyleme gayretinden ileri gelmektedir. Siyaset, sanat, ekonomi, din ve edebiyat gibi dizgeler kültürün alt katmanlarını oluşturmaktadır. Örneğin bir edebiyat eseri erek dile hem de kaynak metnin kültürel niteliklerine bağlı kalarak çevrilecek olunsa, o erek dilin edebiyat dizgesindeki sembolleriyle öncelikle mücadele etmesi ve bunları yenmesi lazım gelir. Bu mecrayı tesir altına alıp, burada kısmen bir dönüşüm 
sağlanması başarıya ulaştıysa, bundan sonra diğer dizgelerle başarı elde etmiş olan semboller iletişime geçecek ve bu reaksiyon zayfflayarak devam edecektir. Sadece bir defa değil, toplumda bireylerin kültürel varlıkları tüketen ve aynı zamanda üreten aktörler olması dolayısıyla öncelikle belirli bir düzeyde bu yeni kültürel sembollere maruz birakılması gerekecektir.

Diğer taraftan kültür çeviri sürecinde çevirmenin hakim olması gereken bir bilgi türü müdür yoksa içselleştirmiş olduğu bir refleks midir? Kaçınılmaz olarak belirli bir kültürde doğup-büyümüş olan çevirmen o kültüre maruz kaldığından belirli bir kültürü refleks olarak içselleştirmiş durumda olacaktır. Ancak sonradan öğrenmiş olduğu kültür... Peki ya iki kültüre birden hakim olanlar hangi kategoride olacak. Herhalükarda çevirmen kültürler arası bir iletişimde rol alacağından ve aktarım malzemesi kültür olacağından dolayı her iki kültüre de vakıf olması lazım (Dizdar, 1999: 105-106). Bu gerek sonradan öğrenme gerekse içselleştirme biçimiyle olsun. Skopos kuramının sahibi Hans J. Vermeer'den (1996: 27) özetlenerek aktarılacak olunursa, gerek sözlü gerekse de yazılı çeviri yapmanın bir metni öylece çevirmek olduğu doğru değildir. Sözlü ve yazılı çevirmenler insan eyleminin bütününde idio, dia ve para kültürleri bilmeli ve çeviri faaliyetinde de skoposuna uygun dikkate almalıdır. Kısaca söylemek gerekirse, çevirmenler çevirilerin gerek üretildiği gerekse tüketildiği yerdeki kültürleri bilmelidirler. $\mathrm{Bu}$ bağlamda çeviri kültür ilişkisi sorunsalına geri dönülecek olunursa, hem çevirmenin kültürü hem çevirmenin yaşadığı kültür, hem de erek ya da kaynak kültür (bazen çevirmen kendi yaşadığı kültürün dışında başka bir erek kültüre orijinal metni çevrimek durumundadır) çeviri olgusunu etkilemektedir. $\mathrm{Bu}$ işin sonuçlanması durumunda, yani ortaya çıkan yeni bir kültürel form ise (yani erek metin) tüketileceği kültürü de etkileyecektir. Diğer taraftan çevirmen de çevirirken kaynak metnin kültüründen etkilenebileceği söylenebilir. Bu nedenle çeviri ve kültür kavramları ele alınıp açıklanmaya çalışıldığında çok boyutlu bir etkileşim sürecinden bahsedilebilir.

Betül Parlak’ın (2006) da vurguladığı üzere “Kültürel ilişkiler ve kültürlerin birbirinden etkilenerek şekillenmesi söz konusu olduğunda gelişme, ilerleme, aydınlanma kavramlarıyla birlikte belli doğruluk kavramları da karşımıza çıkıyor”. Tarihte toplumlar çeşitli vesilelerle etkileşime girmiştir. Bunların başını ticaret ve savaşlar başı çekmektedir denilebilir. Serbest bilim insanlarının da hatrı sayılır bir önemi vardır kültürlerin aktarımı hususunda. Gerek kendilerinin başka bir kültürden belirli bir kültürel birikim elde etmeleri, gerekse daha sonra çevrilmek üzere yanlarında taşıdıkları başka bir kültüre ait eserler kültür aktarımın bir örneğini teşkil etmiştir. Dimitri Gutas Yunanca Düşünce Arapça Kültür adlı eserinde bu bilim insanlarına "uluslararası bilgin" adını vermiştir (2003:29-30). Yunanca-Arapça çeviri hareketinin taşıdığı fikir akımlarının ekonomik, siyasal ve kültürel önemi üzerinde durulması ve bu anlamda kendi alanlarında değişik dillerde çalışmalar yapılması Gutas'ın çevirmenlere bu sıfatı neden layık gördüğünü açıklamaktadır.

\section{Kültür(ün) çevirisi}

Çeviribilim çalışmaları, 1980'lerdeki Kültürel Dönemeç safhasıyla birlikte, geleneksel nedenlere dayalı dil ve kültür ayrımını bir kenara bırakmış ve çeviriyi, bir sistem aktarımından ziyade, bir anlam aktarımı/kültür aktarımı şeklinde algılamaya başlamıştır (Lambert 2006: 165). Çeviriyi iki dil arasında dilsel bir faaliyet gören varsayımı savunan belki de en son eser J. C. Catford'un A Linguistic Theory of Translation: An Essay in Applied Linguistics (1965) adlı kitabıdır (Bassnett, 2000:15). Bu yeni dönemle birlikte, sadece kültür bazlı belli ifadelerin değil, dilin bir bütün halinde kültüre özel kabul edildiği ve çevirinin kültürler arası arabuluculuk rolünün daha hassas ve bir o kadar da karmaşı bir hale büründüğü söylenebilir (Bassnett ve Lefevere,1990). 
Kültür, ne olduğuna dair yapılan sayısız tanıma rağmen (Kroeber ve Kluckhohn, 1952) tam olarak içeriği doldurulamamış kavramlardan bir tanesidir. Raymond Williams bu durumu kelimenin toplumsal ve tarihsel boyutlara sahip olmasına ve farklı akademik disiplinlerde ve birbiriyle uyumsuz düşünce sistemlerinde kullanılmasına bağlamaktadır (1977:49). Latince colere kökünden geldiği belirtilen culture kelimesi (Williams, 1977/2015:49) için Oxford Dictionary aşağıdaki tanımı vermektedir:

"the customs and beliefs, art, way of life and social organization of a particular country or group". / belli bir grup veya ülkenin, gelenek ve inançları, yaşam biçimi ve sosyal organizasyonu (Oxford Advanced Learner's Dictionary 9th Edition, 364) ${ }^{3}$

İngiliz antropolog Edward Burnett Tylor, kültür kavramını, bilgi, inanç, gelenek, örf, adet ve yasa gibi kabul gören ve öğrenilmiş alışkanlıklar ve edimlerden oluşan karmaşık bir bütünlük olarak tanımlamaktadır (1871).

"Culture... is that complex whole which includes knowledge, beliefs, arts, morals, law, customs, and any other capabilities and habits acquired by [a human] as a member of society." / Kültür .., toplumun bir bireyi olarak, insanın edindiği, bilgi, sanat, gelenek, görenek ve diğer beceri ve alışkanlıkları kapsayan karmaşık bir bütündür (Sir Edward B. Tylor,1871).4

Tanımında benzer ifadeleri kullanan John Tomlinson’a göre, kültür, ortak bir düşünme örüntüsü içinde hareket eden insanların anlam inşa etmeye çalıştıkları bir yaşam düzeni içermektedir (1999:18). Bir başka tanım, kültürü, deneyim, davranış ve tutum gibi öğrenilerek ve paylaşlarak aktarılan bilgi ve beceriler bütünü olduğunu ve tüm bunların birbiriyle ilintili davranış kalıplarını sembolize ettiğini belirtmektedir (Tayeb,1992:36).

Kültürün tanımı ne kadar çeşitli olursa olsun, bir bağlam içinde kültüre yapılan referansların algılanması ve tanınması boyutunda bir sorun yaşanmaya bilir. Önemli nokta, her kültürün kendi simgelerini ürettiği ve, Alman filozof Wilhelm von Humboldt'un savunduğu gibi, her dil toplumunun kendi dünya algısından kendi bilgi ve deneyimini kullanarak söz etmekte olduğudur. (1988). Buna ek olarak, Humboldt'un dil-kültür ilişkisi üzerine sıraladığı açıklamalar (2009:121-122), başka bir kültüre ait kültürel simgelerin yine aynı perspektifinden algılanacağı ve ona göre değerlendirileceği fikrini vermektedir. Diğer önemli bir husus, farklı kültürler ve diller arası çevirinin kaçınılmaz olduğu ve çevirilerin durumun hassasiyetine uygun olarak yapılması gerektiğidir. Şöyle ki, farklı inanç ve değer birlikteliği olan dil gruplarının kaynak dil toplumunu yansıtan inanç, değer ve norm sistemini yeterince anlayabilmesi için, öncelikle çevirmenlerin iki dile ait tüm bu kültürel öğeleri layıkıyla kavramak ve bu öğeleri aktaracak en uygun yöntemleri bulmak gibi görev ve sorumlulukları bulunmaktadır (Toury, 1978:200). Dilsel ve kültürel farklılıkları sorun boyutunda algılayan Eugene Nida ve Charles Taber, kültürün çevirisine, aktarılacak öğelerin erek kültür alıcısının gerçeklerine ayak uydurulması gerçeğinin altını çizerek yaklaşmaktadırlar (1969:199). Her ne kadar gerçekleştirilme olasılığı yüksek olsa da, böyle bir yaklaşım, yani, kaynak dil topluluğuna aşina bir öğenin erek kültüre uyarlanmasının gereği, kültüre özgü ifadelerin çevrilemezlik (untranslatability) potansiyeli taşıdığına ve özel muamele gerektirdiğine bir göndermedir. Kavramlar anlaşılsa bile yüklenilen anlam ve çağrışımların farklı olabilme riski nedeniyle kültürel öğenin erek kültüre olduğu gibi aktarılması anlaşllmazhk veya tepkisizlik gibi sonuçlara yol açabilmektedir. Diğer yandan, kaynak kültür öğelerinden arındırılmış ve

Çeviriler çalıșmanın yazarlarına aittir.

Perspectives: An Open Invitation to Cultural Anthropology (Yay. haz.) Nina Brown, Laura Tubelle de González, ve Thomas McIlwraith.2017.4. ISBN: 978-1-931303-55-2 
akıcı bir üslupla okunur hale getirilmiş bir çeviri metin, Venuti’nin çevirinin amacını işaret eden ifadeleri dikkate alındığında, diğeri’ nin çevrilme nedenini ortadan kaldıracaktır:

"The aim of translation is to bring back a cultural other as the same, the recognizable, even the familiar;"/ Çevirinin amacı kültürel farklılığı olduğu gibi, tanınabilir ve hatta bildik olarak geri getirmektir ...(1995:18).

Venuti, Anglo-Amerikan çeviride kabul gören yabancı metnin erek kültür değerlerine indirgeyen bu çeviri yöntemini (ethnocentric reduction) (Can ve Gezer, 2018), bir başka ifadeyle, çeviride yerlileştirme (domistication) stratejisini pek benimsememekte ve böyle bir çeviri metodunu Schleiermacher' in yazarı okura götüren çeviri anlayışılla bağdaştırmaktadır (Munday, 2001: 146).

Kültür aktarımının odak noktası, Nida'ya göre, yapısal farklllıklardan ziyade, genellikle, sözcükler, belli ibareler ve ifadelerden kaynaklanan farklılıklardır (1964:130). Kültürü, Newmark gibi (1988:94), bir yaşam düzeni olarak gören Bassnett, kültürün hem sözcük ve yapı anlamında tüm dil olgusunu bünyesinde barındırabildiğini hem de kendi varlığını sözsel bir göstergeler dizgesi5 olan dil üzerinden idame ettirebildiğini söylemektedir (1980:13-14). Bassnett'in bu tespiti, çeviri kararları öncesinde kültür çevirmenini bekleyen iki önemli sorumluluğun altını çizmektedir:

sözcüklerin erek okur üzerinde oluşturacağı etkiyi göz önünde bulundurma

kültürel öğelerin doğru algılanmasını sağlama

Gerçekte bu iki sorumluluk üzerinden vurgulanan şey dil ve kültür ilişkisinin birbirinden ayrılmaz oluşudur. Böylece, dilsel özelliklerin yanında belli kültürel uzanımlar hakkında geliştirilen farkındalığın çeviri açısından ne derece önem arz ettiği bir kez daha tekrarlanmaktadır. Bu anlamda, Nancy J. Adler’in kültürel farklılıkların analizi için sunduğu bazı kriterler kültür çevirisi için kayda değer bir yol haritası olabilir (1997):

Adler’in analitik çerçevesi:

insanın doğası (the nature of people): İnsanların kendinden olmayana yaklaşımı, gösterdiği duygusallık, inançları, korkuları, aidiyet ve sadakat gibi duyguları hem bireysel hem de toplumsal anlamda farklılıklar gösterebilir.

çevreyle olan ilişkisi (relationship to the external enviroment): İnsanların teknoloji ve çevre arasındaki dengeleri gözetmeksizin doğa üzerinde hakimiyet kurma çabaları içinde olabilirler veya doğayı tahrip etmeden uyum içinde yaşama pratikleri sunabilirler.

diğer insanlarla ilişkisi (relationship to other people): İnsanlar kendilerini bireysel başarılarılyla veya bireysel refah düzeyleriyle tanımlarken, bazıları bu tanımlama içinde kendilerini topluluk değerlerine göre konumlandırırlar.

olaylara etki durumu (the primary mode of the activity): Bazı insanlar olayları oluruna birakma eğilimi göstermekteyken bazıları soğukkanlılıklarını koruyamayarak daha stresli bir yaşam sürdürmektedirler. Bu durum konuşma temposunu, komşuluk ilişkisini ve paraya yüklenen anlamı etkilemektedir

yaşam alanına uyum (orientation to space): Bazı insanlar seyrek nüfuslu yaşam alanlarını tercih etmekte ve mahremiyete büyük önem vermektedir. Bazı topluluklar geniş yeşil sahaları topluma açı alanlara çevirmeyi tercih ederler.

geleneklere bağlılık (temporal orientation): Yüksek teknoloji peşinde olup geleceğe yönelmiş topluluklar yanında tarihini ve geleneğini ve kültürel kimliğini muhafaza etmeyi ön planda tutan toplumlar da bulunmaktadır.

5 Ortega y Gasset, J. (1937). Çevirinin sefaleti ve görkemi üzerine. Rifat, M. (Yay. haz.) Çeviri seçkisi-II.39. 2008. 
Adler’in kültürel farklllıklar için verdiği analitik çerçeve, aynı dil toplumuna ait insanların bile, taşıdıkları sosyo-kültürel özellikler nedeniyle, iletiyi farklı anlayabilme ve/veya yorumlayabilme potansiyelleri olduğunu çağrıştırmaktadır (Metge ve Kinloch, 1978; Platt, 1989).

Kültürel yansımaların önemine dikkat çeken bir diğer isim, Eugine Nida, bu düşüncesini biçimsel ve devingen eşdeğerlik ( formal and dynamic equivalence ) tanımlarıly kategorize etmektedir. Nida'nın biçimsel eşdeğerliği, kaynak dilin biçim ve içeriğinin, erek kültürün gelenek, düşünce ve ifade ediş biçiminin mümkün olan en iyi şekilde korunmasını amaçlamakta ve hedef okuyucuyu kaynak metnin dilsel ve kültürel tercihlerine yaklaştırmayı benimsemektedir. Buna karşın, kaynak dilin uyandırdığı duygu ve algının erek alıcı üzerinde yinelenmesi devingen eşdeğerliğin en belirgin özelliği olarak sunulmaktadir (1964:129).

Kültürel farklılıkları kelime bazında ele alan Peter Newmark bunların çeviriye olan yansımalarını beş başlık altında toplamaktadır (1988:95-102):

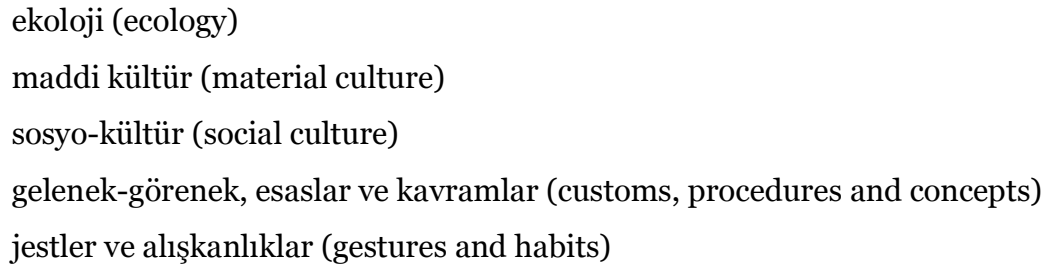

Maddi kültür başlığı altında kategorize edilebilecek kültürel ifadeler arasında en kapsamlı olanını, Newmark, yiyecek bildiren sözcüklere ayırmaktadır. Bunun nedenini, yabancı öğelerin bu tür sözcüklerde varlıklarını daha çok hissettirmesiyle açıklayan Newmark, maddi kültür öğesini, isim babah̆̆ (eponym) terimi üzerinden vermektedir: burada, aşina olunan geleneksel veya iyi bilinen bir ismin, farklı kültürel geçmişe sahip birine, doğru aksettirilememe durumu söz konusudur.

Diğer başlıklardan, jestlerin ve alışkanlıklara ilişkin olanı için Newmark, sadece ima edilip detaylı açıklanmadığı metinlerde çevirinin zorlaştırdığına değinmektedir. Böyle bir senaryo içinde, kaynak dil okurunun arka alan bilgisinin yetersizliğini hesaba katacak çevirmen, en basit ifadelerin bile kültürden kültüre farklı anlamlar taşıma riskini alarak, kültüre özel belli yapı ve ifadeleri ya detaylandırmak ya da yok saymak zorunda kalacaktır (1988:103).

Yukarıda verilen kategorilere ait olup bulunduğu kültürün gerçeğini yansıtan, şüphesiz, sayısız nesne ve kavram bulunmaktadır. Bu söz konusu nesne ve kavramlar başka kültürde mevcut olduklarında dahi veya diğer kültür için hiçbir şey ifade etmediklerinde durumda bile metni ve metnin oluşturulduğu bağlam açısından çevirmenin sorumluluğu altında olduğu bilinmelidir. Bu gerçeğe kültürel yansımaların cereyan ettiği ilgili senaryolarda dikkat çekmeye çalışan Newmark, tıpkı Nida gibi, çeviri kararlarını etkileyen iki önemli sınırlamadan söz etmektedir: ya anlamı olduğu gibi vermek (semantic translation), ya da sadece kastedilen duyguyu hissettirmek (communicative translation) (Newmark, 1981). Verilecek karar ne olursa olsun, anlamın erek kültüre doğru olan yolculuğunun kayıpsız tamamlanmayacağı gerçeği, çeviriyi farklı kıyılarda sona eren bir deniz yolculuğuna benzeten hukuk kökenli bir Alman tarih-dilbilimci Jacob Grimm tarafından, yıllar önce dillendirilmiş olması, ilginçtir (aktaran Neubert, 2002:71, Grimm, 1847).

Kültür kavramı, dile ait her türlü özelliği yansıtması, kendine ait her katmanda bir algı karmaşası içermesi ve sınırlarının belirsizliği nedeniyle, çeviri yapılması güç bir hale dönüşmektedir (Motzkin, 
1996:265). Belirgin olan diğer bir husus, kaynak metnin anlaşılması için diğer kültürün tanınması gerekmektedir. Bunun için gerekli işbirliği ve ortamı çevirinin sağlayabileceği ön yargısına, Jiri Levy'nin çeviriye yakıştırdığı kültürel ve tarihsel birleştirici rolüne bakarak, rahatlıkla varılabilir (2011:89). Bu anlamda, çeviriyi bir iletişim olayı olarak gören ve çevirinin kendisini, diğer kültüre ait dünyayı algılatmasıyla ifade edebileceğini söyleyen Schleiermacher, her iki kültüre ait koşullartn yok sayılamayacağını belirtmektedir (1992:51-52)6 ${ }^{6}$ Schleiermacher’in sözünü ettiği kültüre ait koşullarla deneyim olgusunu kastettiği varsayılırsa, bu koşulların tamamen insani, belli yaşanmışlıkları, ritüelleri, sorunları ve açmazları kapsadığı düşünülebilir. Sosyal-antropoloji alanının önemli isimlerinden E.E. Evans-Pritchard tarafından türetilen kültürün çevirisi (translation of culture) (1971) terimi tam olarak bu anlayışı sergilemektedir: Evans kültür çevirisinin, insan deneyiminin yansıtılması olarak anlaşılmasını istemektedir. Getirdiği açılklamaya devam eden Evans, kültür çevirisinin, diğer kültüre ait değerleri asimile etmeden veya deneyimlerin gerçeğinden farklı biçimde aktarılmasına olanak vermeden yapılması anlamına geldiğini de eklemektedir (Evans-Pritchard, 1965).

Diğer taraftan Otto Kade (1968) her şeyin aktarılabilir olduğunu söylese de, her şey aktarılmalı mıdır, sorusu da sorulmalıdır. Kültürün belirli bir yerele ait olduğu ve dönüşmemesi/dönüştürülmemesi konusunda çaba harcanması gerektiğine dair görüşler bulunmaktadır. Asıl çeviri yoluyla aktarılması gereken medeniyettir ya da medeniyetten filizlenmiş varlıklardır. Medeniyet bir ilerleyiş biçimi, belirli bir toplumun ya da birden fazla toplum kümesinin ortak paydada ürettiği ve evrensel olma kabiliyetine sahip bilgi diye tarif edildiğinde, çevirisinin nasıl yapılacağı konusu gündeme gelmektedir. Nitekim medeniyet kültürün eseri ve sonucudur. Medeniyet kavramılla kıyaslandığında, kültür yereli ilgilendirmektedir ve yerele işaret etmektedir. Bu yönüyle medeniyetin altında konumlandırılabilir.7 $\mathrm{Bu}$ açıdan bakıldığında beynelmilel ortak değerler seviyesindeki medeniyete ait varlıkların çevrilmesinde ve bu değerlerin kaynağı durumundaki kültürün aktarılmasında iki farklı çeviri stratejisinin benimsenmesinde yarar vardır: medeniyette ait varlıklar çevrilirken yerelleştirici bir strateji izlenirken, kültüre ait varlıkların çevirilerinde okurun yazara götürülme prensibi kabul görmeli ve bu bakımdan yabancılaştırıı bir yönteme başvurulmalıdır.

\section{Kültür çevirisinde temas alanları}

Kültür, varlığının temeli olan insanı, değer yargılarından davranışlarına, alışkanlıklarından, inançlarına ve düşünce yapısına kadar yönetme ve şekillendirebilme gücüne sahiptir. (Blackburn, 2009: 86). Merkezinde insan olan çeviri sosyal yaşamın bir parçası olarak gerçekleştirilmektedir. Sonuç olarak, çevirinin kültürel bir eylem olması ve parçası olduğu kültürün bireyleri tarafından icra edilmesi bir iletişim aracı olan çevirinin konumunu daha etkin ve anlamlı kılmaktadır. Çünkü sosyalleşme bireyler arası etkileşimi tetiklemekte ve bu etkileşim iletişime olan ihtiyacı açı̆̆a çıarmaktadır. Oxford Üniversitesi profesörlerinden dilbilimci Roy Harris’in açılış dersinde dile getirmiş olduğu, iletişim dilden önce gelir iddiası (1978), iletişim ihtiyacının önceliğine olduğu kadar dilin daha uzun bir sürecin uzantısı olduğuna bir göndermedir. Bu anlamda, Doris Bachman-Medick, kültürler arası çeviriyi diller arası çevirinin ötesinde görmekte ve çevirinin bağlam ve işleve göre anlam kazanan kültürler arası bir iletişim aracı olduğuna işaret etmektedir (1997).

\footnotetext{
$6 \quad$ Friedrich Schleiermacher'in ilki ders notları olarak baslan On the Different Methods of Translating isimli makalesi daha sonra Berlin Kraliyet Bilim Akademisi 24.06.1813 tarihli toplantısında aynı isimle bildiri olarak sunulmuştur.

Fatih Simsek, Muharrem Tosun (2017). "The Effect of Translations on Cultural Change from The Ottomans to The Turkish Republic”. International Journal of Languages' Education and Teaching - Vol.5-4 - pp.395-408 - ISSN : 2198-4999 - DOI : $10.18298 /$ ijlet.2419-
} 
Küreselleşen dünyada ve sıklıkla yaşanan coğrafi göçlerin zemin sağladığı bir ortamda geleneksel ve kimliğini koruyan bütünsel kültür düşüncesinin sorgulanması ve yerine bütünü oluşturan parçalara odaklanılması yaşanılan çevreye uygun çeviri uygulamalarını teşvik etmektedir (Bhabba, 1994:125). Günümüzde, kültürler arası iletişimin çeviri bünyesinde nasıl inşa edildiği post-yapısalcı bakış açısının kontrolünde tetkik edilmektedir (Canagarajah, 2013:26). Monolitik bir kanıdan daha çok kozmopolit bir benimseyişin savunulduğu bu anlayış, türlü ve karmaşık bir kültür kavramının üzerinde durmaktadır (Atkinson ve Matsuda 2013: 234). Bu nedenle, mozaik bir görünüm sunan bugünün post-modern toplumundaki parçalar arası iletişimi sağlayacak çeviri anlayışının, Joachim Renn'in belirttiği gibi, farklılıklar arası doğal sınırları yansıtma ve onları koruma gibi bir görevi olmalıdır (Akt. Pym, 2017:167, Renn, 2006). Ancak dilin ve kültürün belirleyici olduğu bir ortamda ve farklı dillerin farklı dünya yaşantısına sebep olduğu bir paydada (Sapir Whorf Hipotezi) ${ }^{8}$, kültür çevirisinin, sadece yabancı kültürlerin kavram dünyasını anlamaya yönelik bir araç değil aynı zamanda yanlış anlamayı oluşturan bir durum olduğu da ortadadır (Berg,1997:185-198; aktaran Bachman-Medick, 1997:83). Anlamların bağlamsal farklılıkları bu anlamda önemlidir ve bu olguyu Bronislaw Malinowski iki aşamada dikkate almaktadır (1986:363):

\section{1. kültür bağlamı}

2. durum bağlamı

Kültür bağlamı ahlaki ve estetik değerleri içeren geniş anlamda kullanılırken, daha dar anlamı işaret eden durum bağlamında kelimelerin işlevleri, ilgi alanları ve konuşma eyleminin etkileri ele alınmaktadır.

Kültür çevirisi sürecinde kültürel anlam kurgusunun yapılanmasındaki en önemli faktör kültürün, bir metni oluşturan göstergeler sistemi gibi, belirgin anlam birimlerinden oluştuğu gerçeğidir (BacmannMedick:1998). Semboller, ritüeller, deneyim ve uygulamalar olarak adlandırılabilecek bu anlam parçalarının kültürü bir bütünün olarak yorumlanmasına olan etkisini inceleyenlerden Amerikalı dilbilimci ve antropolog Roger M. Keesing, bolca söz sanatı ya da mecaz içeren günlük dile (Lakoff, 1980:1-5) dikkat çekmektedir. Keesing, insan deneyimlerinin dile getirildiği günlük dilde kullanılan metaforlara veya benzetmelere yüklenecek gereğinden fazla anlam derinliğinin negatif yansımalarına değinmektedir. Yanlış anlaşılma ve yanlış çeviri ihtimallerine yönelik bu kaygl, Keesing'e göre, her dilsel ifadenin abartılı bir şekilde teolojik ya da metafizik bir dünya görüşünün temsili olarak kabul edilmesinden kaynaklanmaktadır (1985:201-2017).

Belli kültürlerde çeşitlilik gösteren düşünce dünyalarının başka kültürlerde anlam daralmasına uğraması kültür çevirisinin ne denli güç olduğunu göstermesi açısından önemlidir (Aoki, 1992:57; aktaran Bachman-Medick, 1997:83). Ancak, kaynak kültür yerine, özellikle erek kültürü temsil eden tarihsel ve sosyal söylem koşullarının benimsenmesi, çeviriyi temsilin temsili konumuna sokabilmektedir (Sperber,1993:162).

Temsil gücü açısından bakıldığında, kültür çevirisi, Edward Said’in Şarkiyatçıllk / Orientailism başlıklı eserinde oryantalist bakış açısını eleştirdiği gibi (1978), dil ve kültür üzerinde bir otorite kurma düşüncesiyle zaman zaman işbirliği içinde görülmektedir. Bu gibi durumlarda, bir kültür içinde farklı ve

Sapir-Whorf hipotezi (1956) adını dilbilimci olan Benjamin Lee Whorf ve Edward Sapir’den alan ve dilin düşünce yapısını etkilediğini ve bunun da dünya algısını biçimlendirdiğini savunan bir kuramdır. Bkz Pym, A. (2010). Exploring translation theories. London: Routledge.9. 
zıt seslerin duyulmasını sağlayan geniş bakış açısına sahip bir çeviri anlayışıyla çeviri otoritesini başkaları adına konuşarak hissettiren bir çeviri yönelimi arasında bir tercihin gerekliliği açıktır.

Tarih boyunca iktidar ilişkileri ve sömürge projelerinde yer verilen kültürel çeviri uygulaması, kendini siyasal anlam boyutuyla da yansitmaktadır (Maier ve Dingwaney, 1995:3). Christina Schaffner'e göre, siyasi iletişim, siyasi söylemlerin sınırların ötesinde de anlamlı kalabilmesi için, çeviriye tabidir (2007:258-284). Özellikle kültürün dönüşüm süreçlerini belirleyen sosyal, kültürel ve iletişimsel uygulamalar noktasında, kültürel dayatmalara gösterilen direnç, Bhabba’ya göre, yeniden yazma / yeniden çevirme (re-writing / re-translation) uzantıları açısından, çevirinin siyasal dili ve çevirinin kültürel dili ikilemi içinde değerlendirilmelidir (1994:241).

Ekonomi, siyaset, reklam, iş dünyası ve birçok alanda bilgiye olan ihtiyaç ve kendisine kolaylıkla ulaşılma hızı, (Fairclough, 1997), diller ve kültürler arası iletişim anlamında çevirinin önemini her geçen gün arttırmakta ve sağlamlaştırmaktadır. Bu gerçekle, kültürel hareketliliğin yansıma sahalarından biri olan yazın edebiyatı, kültürü temsil etme ve kültürleri birleştirme gücüne sahip olması itibariyle, tarihsel ve kültürel farklılıkların tanıtılmasında, çeviriyle birbirlerinin daima tamamlayıcısı olmuşlardır (Berman:2009:432-446).

Diğer kültüre ait yazın edebiyatıyla diyalog temelleri üzerinden yürütülen çeviri-kültür birlikteliği, günümüzde, kültürün dönüşümü yönünde seyreden çeviri uygulamalarına ağırlık vermiş ve bunun sonucunda, Michael Cronin’in tabiriyle, her iki kültürden beslenen bir Üçüncü Kültür (Cronin, 2003:112) ortaya çlkmıştır. Etnografik ve antropolojik çalışma yöntemleriyle beslendiği belirtilen bu yeni kültür çeviri anlayışı (Bassnett 2007:23) hem geleneksel hem de diyalog içinde bulunulan koşut kültür öğelerini işleyerek bir kültür sentezi sunmaktadır. Kültürü dönüştürmeye yönelik bu eğilimi, Emily Apter, Leo Spitzer'ın 1934 yılında Varlık / Being dergisinde yayınlanan Türkçeyi öğrenirken / Learning Turkish 9isimli makalesinde geçen, her dil milli olmaktan önce insanidir, önermesini arkasına alarak savunmaktadır (Apter, 2006:43). Apter’in bu gerekçeyle yaptı̆̆ı, dilin evrenselliği vurgusu, Walter Benjamin'in 1923 yılında kaleme aldığı Çevirmenin Görevi / The Task of the Translator ${ }_{10}$ başlıklı makalesinin genelinde yansıttığı çevrilen yapıtın çeviriyle hayat bulduğu felsefesiyle uyuşmaktadır. Çevirmenin asıl görevini, başka dilin etkisi altındaki o saf dili (die reine Sprache) serbest brrakmak olarak belirlemiş olan Benjamin' e göre, yazın eserlerin kültürler arası ve kozmopolit bir önem kazanmasındaki gerçek pay çeviriye aittir. Benjamin, bu düşüncesini desteklemek için, çeviri olmaksızın yazın eserin sadece belli bir kültüre ait olarak kalacağı ve asıl anlamını asla bulamayacağı, varsayımlarını kullanmaktadır. Bu nedenle, tarihsel süreçte dilin ve yaşam şeklinin mutasyona uğrayacağı görüşünden hareketle Benjamin, bütünselliği, kültürel değerler, tarihsel oluşum ve dillerin akrabalı̆̆ gibi olguların önüne koymaktadır ([1923] 2008:29-33).

Buna karşın, kültürel farklılıkların bilinmesinin gerekliliğine vurgu yapan ve çeviri yazında yabancı unsurların tutulmasını (foreignization) tavsiye eden Gayatri Chakravorty Spivak, erek kültürü her anlamda tanımanın, kendini diğeriyle tanımlamanın ve/veya karşılaştırmanın yolu olarak görmektedir. Spivak, gücün diline doğru yapılan edebi çevirilere kültürel kimliğin kaybolma endişesinden dolayı eleştiri getirmekte ve sömürgecilik sonrası kuram, feminizm ve yapısöküm söylemlerinin birleştiricisi kimliğiyle, yazın eser çevirisinin ideolojik yüzüne dikkat çekmektedir (2000:407).

$9 \quad$ Leo Spitzer. Learning Turkish in Varlik [Being], Nos. 19, 35, and 37,1934. Translation by Tulay Atak.

$10 \quad$ Walter Benjamin selected writings volume 1 (1913-1926) the task of the translator (253-263) THE BELKNAP PRESS OF HARVARD UNIVERSITY PRESS (2002)

http://users.clas.ufl.edu/burt/deconstructionandnewmediatheory/walterbenjamintasktranslator.pdf 
Çevirinin pedagojïye olan yaklaşımını disiplinler arası doğası belirlemekte ve günümüzde küresel çağın gerçeklerini anlamak ve iletmek için esashı bir pedagojik çeviri yaklaşımı güdülmektedir (Carrove, 1999:6-8). Bu yeni pedagojik çeviri anlayışı, farklı akademik disiplinlerin parametrelerini yeniden biçimlendirmekte ve diğerini çevirinin olma nedeni olarak görmektedir (Rabassa, 1989:1). Bu nedenle, kaynak dilin doğasında var olan yeni olguları ve fikirleri erek kültüre bir zenginlik olarak katmak, erek kültür insanlarına yeni ufuklar açmak ve farklı gelenek ve inançların varlığından onları haberdar etmek gibi görevlerle donatılmıştır. Böyle bir felsefeyi No Two Snowflakes Are Alike: Translator as Metaphor başlıklı makalesinde dile getiren Gregory Rabassa, kültürel ön yargıların yıkılması ve insanları hem birey hem kültür olarak özgün kılan farklılıkların benimsenmesi açısından, önemsemektedir (Rabassa, 1989:3).

Bilgiye en kısa zamanda ulaşma talebi, çeviriyi, kitle iletişim çağının vaz geçilmez enstrümanlarından biri yaptığı gibi (Bassnett ve Lefevere, 1990), sinema, reklam, internet, radyo-TV, gazete ve/ veya kitap gibi görsel-işitsel kitle iletişim kanalları üzerinden, kültürel farklılıkların aktarılmasında en önemli unsur haline getirmektedir (Bassnett, 1996:1). Çevirinin aynı zamanda bir anlamlandırma süreci olması (Tymoczko, 2007: 265), sanatsal, kültürel ve ekonomik hassasiyetlerin bir arada tutulduğu bir mecrada, yedinci sanat olarak bilinen sinemayı, kültürel değerlerin canlı tutulması ve diğer kültürlere ait farklılıkların en vurucu şekilde sergilenmesi açısından bir adım öne çıkartmaktadır. Her filmin bir şekilde o kültür hakkında belgesel niteliğinde bilgi veriyor olması, ait olduğu kültüre özgü bolca imge sunması ve özellikle seslendirme (dublaj) (dubbing) ve alt yazı (subtitling) teknikleriyle daha geniş kitlelere ulaşılabilirliği, bu tespiti haklı çıkarmaktadır.

Filmleri iki kültürlü ürünlere dönüştürüveren seslendirme ve alt yazı teknikleri, kültürün açtı̆̆ı iki önemli cephede savaş vermektedir: kültürü temsil eden imge düzeneğinde ve kendine ait karakteristik özellikleriyle dil boyutunda. Sürecin sonunda, erek kültür üzerinde yaratılmak istenen etkiye göre, ya kültürel imgenin filmde kullanılan dili tamamlaması ya da metin ila imge arasında tutarsızlık yaşanması beklenmektedir. Tasarlanan algının sonucunu aksettiren bu durum, HolzMänttäri'nin çeviriye ilişkin eylem kuraminda (translational action), translatum (Akt. Reiss ve Vermeer, 1984-2014:103/HolzMänttäri, 1984) ${ }^{11}$ olarak adlandırılmaktadır. Böylece, dublaj ve/veya altyazı çevirisiyle işlevinin alıcıya göre değiştirildiği böyle bir translatum, tüm diğer kitle iletişim kurgularına ait çeviri ürünlerinin yaptı̆̆ gibi, erek kültürü şekillendirme ve aynı zamanda diğer kültürlerle birleştirme çabaları içindeki yerini almaktadır (Tymockzko, 2007:25-304).

Görsel-işitsel çevirinin cereyan ettiği alanlardan biri, bolca kültürel öğe içeren, reklam çevirileridir. Önemli bir sosyal olgu kabul edilen reklamlar (Valdes, 2011:94), mizah ve kültürel klişeler gibi, dilin sanatsal ve sosyo-kültürel ara yüzünü yansitmaktadırlar (Sidiropoulou, 2008:338). Nihayetinde, reklamın asıl ve tek amacının alıcıyı reklam ürününü almaya ikna etmek olduğuna göre, ikna etme yöntemleri, kültüre özel ve kültürle şekillenen belli süreçleri yürütmektedir (a.g.e). Bu durum, kültürler arası görsel-işitsel çeviri platformunda, bir yandan kültürün çeviri yoluyla adaptasyon sürecine (transadaption) (Gambier, 2004:5; aktaran Munday, 2012:271) bir örnek teşkil etmekte, diğer yandan çevirinin bilinçli bir seçim ve kurgu eylemi olduğunun görülmesine yardımcı olmaktadır (Tymockzko ve Gentzler, 2002:xxi).

Çeviri, görüldüğü üzere, kültürün sosyal boyutunun oluşturduğu her türlü yaşamsal ortamda uygulanmakta ve özellikle kültürler arası çeşitliliği açığa vuran semantik ve sentaktik düzlemlerde yardımına fazlasıyla ihtiyaç duyulmaktadır. Diller ve kültürler arası sözcüksel iletişim için gerekli olan

$11 \quad$ Bkz: Routledge Encyclopedia of Translation studies (2008) (Yay.haz.) Mona Baker ve Gabriela Saldanha.117. 
deyimler, atasözleri, isim tamlamalar, günlük tabirler ve terimler ve bu türden adlandırmalar, kültürel ve tarihsel gelişimlerini yeni kullanım alanları yanında farklı yan anlamlar ve çağışımlar kazanarak veya kaybederek tamamlayabilmektedirler. Çevirisiyle birlikte kaynak kültürden uzaklaşma anlamına gelebilecek bu her iki durum için, Hervey ve Higgins, compromise in translation (çeviride uzlaşma-taviz) tabirini kullanmaktadır (1992: 28-34). Bu tabirden, kaynak metne hakkını verme çabasının uzlaşma gerektirdiği, ancak verilen tavizler sonucunda erek metinde çeşitli çeviri kayıplarının yaşandığı, anlamı çıkarılabilir. Son tahlilde, Hervey ve Higgins' in düşüncelerine göre, her türlü kültür aktarımı, kaynak kültüre özgü özelliklerin erek kültürünkine bir şekilde benimsetilmesi, anlamına gelmektedir.

Kültürel sözcüklerin kullanım alanlarını kategorize edenlerden Vinay ve Darbelnet, çeviri amaçlı yaptıkları sınıflandırmayı zamansal kavramlar, meslekler ve pozisyonlar, yiyecek içecek isimleri gibi sosyal hayatın çeşitli katmanlarından oluşturmaktadırlar (1958). Bunlara ek olarak verilebilecek, ölçü ve para birimleri, kurumlar ve giysiler (Catford, 1964:9-37), müzik ve spor terimleri ve bu etkinliklerin cereyan ettiği sosyal mecralar ve daha niceleri kültüre özel, zamana özel ve bireye özel adlandırılan olgulardır (Santoyo, 2010:15). Bu olguların, kültürleri bir birinden ayırmaya yardımı olsa da, çeviri açısından zorluklar arz ettikleri açıktır. Ve bu zorluklara, anlam gelişimini tamamlayana dek sürekli değişim içindedir savının sahibi, Walter Benjamin'in penceresinden bakıldığında (1923:29), çevirinin olasılığı ve imkansızlı̆ı üzerine süre gelen tartışmaya katılmamak, daha doğrusu, taraf olmamak içten bile değildir.

\section{Sonuç}

Kültür, dil olgusu dışında, kendini belirleyen gelenek, görenek, dünya anlayışı, düşünme biçimi, değer yargısı gibi unsurlarla birlikte, zaman ve mekana uyum göstererek algıyı etkileyebilmektedir. Kültürü anlama, algılama ve çevirme süreci, dilin özelliklerini dikkate alan bir dünya görüşü gerektirmektedir. $\mathrm{Bu}$ anlamda içinde bulunduğu kültürü, göstergeler ve simgelere yüklediği anlamlarla, daha anlaşır kılmak isteyen toplum, göstergebilimsel açıdan kültüre metin özellikleri katmaktadırlar. Bu da kültürü esasında çevirilebilir nitelikler kazandırmaktadır. Bu yüzden, Doris Bachman-Medick, kültürün bütününü oluşturan ve metin özelliği taşıyan kültürel anlam taşıyıcılarının, kendilerini yorumlayan ve temsil eden metin odaklı çeviri uygulamalarına tabi tutulmakta olduğunu söylemektedir (2012:103). Ayrıca, kültür çevirisinin kültürler arası bir aktarımdan kültürel kodlamaların aktarımına doğru bir genişleme gösterdiğini belirten Bachman-Medick, metin aktarımında olduğu gibi, salt dilsel öğelerin aktarılmadığını, bu tür çeviri uygulamalarının düşünce biçimi, dünya görüşü ve eylem şeklini de içine alan, kültürel farklılıkları belirleyen ve kültürler arası iletişimi baş unsur haline getiren bir anlayışta ve yaşanılan ortama uygun gerçekleştirildiğinden söz etmektedir. Bachman-Medick' e göre, kültür anlayışında ve kültürlerin karşılaştııılmasında meydana gelen değişimler doğrultusunda, kültür ve çeviri arasında belli temas alanları gelişmekte ve bunun sonucunda kültür gelişmektedir (2012:106109).

Kültürler, direnç, farklılık, yönlendirme, şekillendirme ve kaynaştırma süreçleri olarak değerlendirildiğinde, çevirinin tasarım ve kurgu görevinden faydalanıldığı ortaya çımaktadır. Bunun dışında, erek kültürü anlamanın gerekliliği yabancı dil öğrenme ve kültürü çevirme zorunluluğu anlamına gelmektedir. Sömürgeci ve oryantalist çeviri eylemleri, kültür çevirisinin, iktidar-güç ilişkileri ve egemenlik hiyerarşi çerçevisinde geliştirilen söylemlere olan katkısına işaret eden örneklerdir. Coğrafi göçlerin çanak tuttuğu kültürel dönüşümün, geleneksel kimliği ve kültürel bütünlüğü sorgulanır hale getirmesi, yine çeviri pratiğinin gerekçelendirme neticelerindendir. Son olarak, var olan kitle 
iletişim ağının tümünün, metin yoluyla ürettiği ve etkilediği kültürel algıyı, çeviri yoluyla yansıttı̆̆ı unutulmamalıdır.

Kültür çevirisinin beraberinde getirdiği zorluklardan söz edilecek olunursa, en önemlilerinden biri, dünya algımızı farklı kategorize etmemizi sağlayan sözcüklerin, zaman içinde değişen anlamları ve kullanım alanları olduğu görülecektir. Bir diğer çeviri zorluğu, günlük hayatta kullanılan söylemlerin ve eylemlerin çevrilmesinde yaşanmaktadır. Bu paralelde, yerel kavramsallaştırmaların kaynak kavramlar kullanılarak tanımlanması ayrı bir sorun kategorisi oluşturmaktadır (Clifford, 1986:115). Bunlara ek olarak, zaman, mekan, güç, statü ve cinsiyet gibi dış etkenlerin sosyal ilişkileri düzenliyor olması ve kültürden kültüre farklılık göstermesi kültürün çevirisini zorlaştıran bir başka etmendir.

Sonuç olarak, kültür(ün) çevirisi diller arası çevirinin ötesini gösteren bir uygulamadır; erek kültürü anlama, onunla kaynaşma, onu temsil etme, onunla iktidar ilişkileri kurma, ve onun dünya görüşünü yansıtma gibi eylemler içermektedir. Ve tüm bunları yaparken, kültürel farklılıkları belirlerleme ve şekillendirme potansiyeline sahip kültür(ün) çevirisi, kültürel farklılıkları sosyal iletişim ve etkileşim dünyasının ayrılmaz unsurları haline getirebilmektedir.

\section{Kaynakça}

Adler, N.J.( 1997). International dimensions of organizational behavior. 3. baskı. Cincinnati, OH: Shout-Western College Publishing.

Apter, E. (2006). The translation zone: a new comparative literature. Princeton University Press.

Atkinson, D. ve Paul K. Matsuda (2013). Intercultural rhetoric: a conversation - the sequel. (Yay. haz.) Diane B. ve Gayle N. Critical and corpus-based approaches to intercultural rhetoric. University of Michigan Press.

Atkinson, Dwight and Paul K. Matsuda (2013) 'Intercultural Rhetoric: A Conversation - The Sequel', in Diane Belcher and Gayle Nelson (eds) Critical and Corpus-based Approaches to Intercultural Rhetoric. Ann Arbor: University of Michigan Press, 227-42.

Bachman-Medick, D. (2013). Kültür antropolojisi ve çeviri. (Yay. haz.) Yücel, F. Çeviribilim paradigmaları: çeviri seçkisi içinde. ÇNK.

Bachmann-Medick, D. (2012). Culture as text: Reading and interpreting cultures. (Yay. haz.) Neumann, B. and Nünning, A. Travelling concepts for the study of culture içinde.Berlin/Boston: De Gruyter, 99-118. URL: http://bachmann-medick.de/wpcontent/uploads/2013/07/Culture\%20as\%20 Text\%2oDruckfassung.pdf

Bachmann-Medick, D. (2017). Cultural Turns: A Matter of Management?. (Yay. haz.) Küpers, W. Sonnenburg, S. ve Zierold, M. Management - culture - interpretation: rethinking management perspectives and impacts of cultural turns and beyond içinde. Springer VS. DOI 10.1007/978-3658-16983-1

Bassnett, S. (1980). Translation studies. London: Routledge.

Bassnett, S. (2007). (Yay. haz.) P. Kuhiwczak ve K. Littau. A companion to translation studies içinde. Clevedon/Buffalo/Toronto: Multilingual Matters, 13-23.Piotr Kuhiwczak and Karin Littau

Bassnett, S. and Lefevere, A. (1990). Translation, history and culture. London: Pinter.

Bassnett, S. ve Lefevere, L. (1998). Constructing cultures: essays on literary translation. Clevedon: Multilingual Matters.

Benjamin, W. (2008). Çevirmenin görevi. (Yay. haz.) Mehmet R. Çeviri seçkisi -2 içinde. (25-35). İstanbul:Sel.

Benjamin, W. (1923). The task of the translator. Selected writings içinde (1913-1926). Vol.1 (253-263) The Belknap Press of Harvard University Press (2002) 
http://users.clas.ufl.edu/burt/deconstructionandnewmediatheory/walterbenjamintasktranslato r.pdf

Bermann, S. (2009). Working in the and zone: comparative literature and translation. Comparative literature içinde. 61(4):432-446. DOI: 10.1215/00104124-2009-025

Bhabba, H.K. (1992). Postcolonial criticism. (Yay. haz.) S. Greenblatt, G. Gunn. Redrawing the boundries: the transformation of English and American literary studies içinde.New York.437465 .

Bhabba, H.K. (1994). The location of culture. London.

Blackburn, S. (2009). What do we really know?... London: Quercus.

Can, M. Zahid ve Gezer, G. (2018). Haber çevirilerinde yerlileştirme stratejileri olarak etnomerkezci eritme ve saldrrgan sadakat. Tarih okulu dergisi (TOD) /Journal of history school (JOHS).11,38(2).1-37. DOI No: http://dx.doi.org/10.14225/Joh1460

Canagarajah, S. (2013). Translingual practice: global Englishes and cosmopolitan relations. Abingdon: Routledge.240. https://doi.org/10.1002/tesq.115

Canagarajah, S. (2007) 'Lingua Franca English, Multilingual Communities and Language Acquisition', The Modern Language Journal 91, 923-39.

Carrove, M. S. (2000).Towards a theory of translation pedagogy based on CAT tools for Catalan and English non-literary texts Universitat de Lleida. Departament d'Anglès i Lingüistica http://hdl.handle.net/10459.1/63619

Catford, J.C. (1965). A linguistic theory of translation: an essay in applied linguistics. Oxford University Press.

Chesterman A., ve Williams J. (2002). The map: a beginner's guide to doing research in translation studies. Manchester: St. Jerome. ISBN 1-900650-54-1 (pbk).

Clifford, J. (1986). On ethnographic alegory. (Yay. haz.) J. Cifford ve G. E. Marcus. Writing culture içinde. London.Berkeley.98-121

Cook, G. (2003). Applied linguistics. USA: Oxford University Press. Chapter 6.

Cronin, M. (2003). Translation and globalisation. Routledge.

Davis, K. (1977). Human behavior at work. New York: McGraw-Hill Book Company.

Dizdar, D. (1999). Skopostheorie. Handbuchtranslation. Hrsg. Petter Schmitt. Stauffenburg. Tübingen.

Dingwaney, A. ve Maier, C. (1995). Between languages and cultures: translation and cross-cultural texts. Pittsburgh Series in Composition, Literacy \& Culture.

Gentzler, E. (2017). Translation and rewriting in the age of post- translation studies: new perspectives in translation and interpreting studies. Routledge.

Fairclough, N., ve Wodak, R. (1997). Critical Discourse analysis. (Yay.haz.) Teun van Dijk. Discourse studies: a Multidisciplinary Introduction-2: discourse as social interaction., 258-284.

Geerzt, C. (1983). From the native's point of view: on the nature of anthropological understanding. Local knowledge: further essays in interpretive anthropology içinde.New York. 55-70.

Gregory, R. (1989). Gregory Rabassa. Contemporary authors autobiography series içinde. 9:191. Detroit: Gale Research.

Gutas, Dimitri (2003). Yunanca Düşünce Arapça Kültür. İstanbul: Kitap Yayınevi.

Harris, R. (1978) Communication and language: an inaugural lecture delivered before the University of Oxford on 24 February 1978. Oxford: Clarendon Press.

Hervey, S.G.J. ve I, Higgins. (). Thinking translation : a course in translation method, French-English. Taylor and Francis Routledge. 
Humboldt, Wilhelm F. von. (1988). On language: on the diversity of human language construction and its influence on the mental development of the human species Peter Heath (Çev) . Cambridge: Cambridge University Press.

Kade, Otto (1968). Zufall oder Gesetzmäßigkeit in der Übersetzung. Leipzig

Keesing, R.M. (1985). Conventional metaphors and anthropological metaphysics: the problematic of cultural translation. Journal of anthropological research. 41:201-217

Kroeber, A. L., ve Kluckhohn, C. (1952). Culture: A critical review of concepts and definitions. New York: Vintage Books.

Lakoff, G. ve Johnsen, M. (1980). Metaphors we live by. Chicago Press.

Lambert J., 2000, Cultural studies, the study of cultures and the question of language: facing / excluding the new millennium. Delabastita, D., L. D'hulst, L. ve R. Meylaerts, R. (Yay. haz.). Functional approaches to culture and translation içinde. 2006. Amsterdam/Philadelphia.163-171.

Lefevere A. (1992). Translation: history, culture: as a source book. London-New York. Routledge.

Levý, J. (2011). The art of translation. Zuzana J. ve Patrick C. (Yay. haz.) Amsterdam, Philadelfia: John Benjamins.

Malinowiski, B. (1862): Sex, culture, and myth. London: Rubert Hart- Davis.

Malinowski, B. (1935). Coral gardens and their magic-2: the language of magic and gardening: London.

Mardin, Şerif (2011). Din ve İdeoloji. İstanbul: İletişim.

Metge, J. ve Kinloch, P. (1978). Talking past each other: problems of cross-cultural communication.Wellington: Price Milburn.

Motzkin, G. (1996). Memory and cultural translation. (Yay. haz.) Budick, S. ve Iser, W. The translatability of cultures: figurations of the space between. Stanford. 265-281.

Munday, J. (2012). Introducing translation studies: theories and applications.London: Routledge.

Nergaard, S. ve Arduini, S. (2011). Translation: a new paradigm. Translation: an interdisciplinary journal. the inaugural issue. 8-17. http://translation.fusp.it

Newmark, P. (1988) A textbook of translation. Hertfordshire: Prentice Hall. https://archive.org/stream/ATextbookOfTranslationByPeterNewmark/a\%20textbook\%20of\%2 otranslation\%2oby\%2opeter\%2onewmark_djvu.txt

Newmark, P. (1988) Approaches to translation. Hertfordshire: Prentice Hall.

Nida E., Taber C.(1969). The theory and practice of translation. Leiden.

Nida, E. A. (1964) Towards a science of translation, with special reference to principles and procedures involved in Bible translating. Leiden: Brill.

Parlak, B. (2002). Popüler Kültür ve Çeviri. http://ceviribilim.com/?p=240, Erişim Tarihi: 20.09.2019.Çeviribilim. İstanbul

Paul Vinay, P. ve Darbelnet, J. (1958). A methodology for translation. (Yay. haz.) L. Venuti. The translation studies reader içinde. 84-93. London: Routledge.2000.

Pym, A. (2008).Translation and the philosophy of dialogueTranslation and the philosophy of dialogue (Arnaud Laygues). Neuphilologische Mitteilungen içinde. 109(1):106-110

Rabassa, G. (1989). No two snowflakes are alike: translator as metaphor. (Yay. haz.) J. Biguenetve R. Schulte. The Craft of Translation içinde.1-1. Chicago ve London: The University of Chicago Press.

Reiß, K. ve Vermeer, H.J. (1984/2014) Towards a general theory of translational action: skopos theory explained. Translated from the German by Christiane Nord English reviewed by Marina Dudenhöfer First published 1984 by St. Jerome Publishing. Published 2014 by Routledge 
Renn , J. (2006). Indirect access: complex settings of communication and the translation of Governance. (Yay. haz.) A. Parada ve O. Dīaz Fouces. Sociology of translation.Vigo: Universidade de Vigo.193 $-210$.

Santoyo J.-C. (2010). Translation and cultural identity: competence and performance of the authortranslator. (Yay. haz.) M. Muñoz-Calvo ve C. Buesa-Gomez. Translation and cultural identity: selected essays on translation and cross-cultural communication içinde. 13-32. London: Cambridge Scholars Publishing.

Sapir,E. (1956). Selected writings in language, culture and personality. Berkeley: University of California Press.

Schäffner, C. (2007). Politics and Translation. (Yay. haz.) P. Kuhiwczak ve K. Littau. A companion to translation studies içinde. Clevedon/Buffalo/Toronto: Multilingual Matters, 134-147.

Schleiermacher, F. (1813). On the different methods of translating. R. Schulte ve J. Biguenet (Yay. haz.) Theories of translation: an anthology of essays from Dryden to Derrida içinde. (36-54). The University of Cicago Press. 1992.

Sidiropoulou, M. (2008). Cultural Encounters in Advertisement Translation. Journal of modern Greek studies, $26,337-362$.

Sperper, D. (1993). Interpreting and explaining cultural representations. (Yay. haz.) G. Palson. Beyond boundries içinde. Oxford. 162-183.

Spivak, G. Ch. (2000). The politics of translation. (Yay.haz.) L.Venuti. The translation studies reader içinde. London. New York: Routledge.

Steiner, G. (1975). After Babel: aspects of language and translation. London.

Stierstorfer, K. ve Gomille, M. (2008). Cultures of translation. Cambridge.

Tayeb, Monir H. (1992). The global business environment: an introduction. London: Sage Publications.

Tomlinson, J. (1999). Globalization and culture. Cambridge: Polity Press.

Tylor, Edward B. (1871) Primitive culture: researches into the development of mythology, philosophy, religion, language, art, and custom. London: John Murray. Print.

Tymockzko, M. ve Gentzler, E. (2002). Translation and power. University of Massachusetts Press.

Tymoczko, M. (2007, 2010). Enlarging translation, empowering translators. London: Routledge. ISBN-13: 978-1900650663

Underhill, J. (2009) Humboldt, worldview and language. Edinburgh University Press.

Valdés, C. (2011). An empirical approach to the reception and perception of television advertising. International journal of translation, 23(2), 94-104.

Vardar, B. (1982). Dilbilimin temel kavram ve ilkeleri. Ankara: TDK.

Venuti, L. (1998). The scandals of translation: towards an ethics of difference. London and New York: Routledge.

Venuti, L. (1995). The translator invisibility: a history of translation. London - New York: Routledge.

Williams, R. (1976). Keywords: a vocabulary of culture and society. New York: Oxford University Press.

Williams, R. (1977). Culture and society: 1780-1950. Middlesex: Penguin Books.

Wittgenstein, L. (1958). Philosophical investigations. Translated by G.E.M. Anscombe. New York: Macmillan. 